\section{Periodontitis, cardiovascular disease and pregnancy outcome - focal infection revisited?}

\author{
M. Ide*1 and G. J. Linden ${ }^{2}$
}

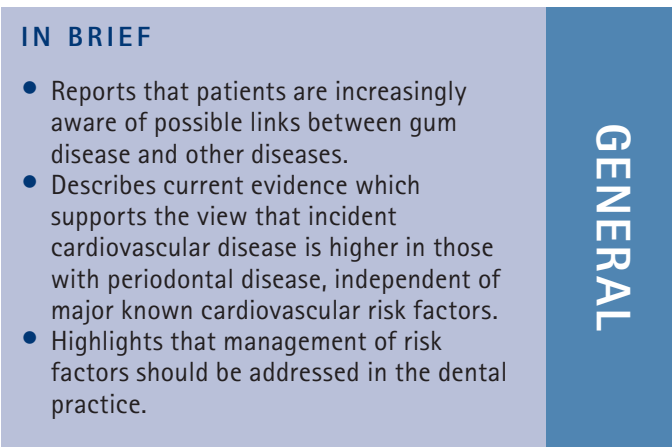

\begin{abstract}
Over the last two decades there has been a renewed interest around the possible effects of periodontal disease on both cardiovascular health and pregnancy outcome (among other diseases), a topic which has interested science for hundreds of years. These have led to a range of studies, workshops and consensus documents being published, with corresponding coverage in general and professional media. In this article the authors summarise the history and supporting theories behind such associations, whether clinical studies have been able to confirm these and what this might mean for general practitioners who are questioned on this topic by patients.
\end{abstract}

\section{INTRODUCTION}

In the fourth century BC Hippocrates, a Greek physician known as 'the father of medicine', was reported to have attributed the cure of a case of arthritis to the extraction of a tooth. This is probably the earliest recorded description of a possible link between oral infection and a systemic condition. Was this an astute observation by one of the first physicians or did it represent two events that happened in quick succession and were unrelated? Benjamin Rush, an American who was one of the signatories of the Declaration of Independence, stated in 1801 that 'he had added to the observations of other physicians in pointing out a connection between the extraction of decayed and diseased teeth and the cure of general diseases'. ${ }^{1}$ It is difficult to appreciate the levels of oral infection associated with untreated caries and periodontal disease that were prevalent at the time. In the nineteenth century the term pyorrhoea ('flow of pus' derived from Sanskrit) was in common use to describe periodontal disease.

In 1900 William Hunter, a British doctor, developed the theory of focal infection which was to have a major impact on dentistry. He identified links between oral

'Dental Institute, King's College London, Great Maze Pond, London, SE1 9RT; ${ }^{2}$ Centre for Public Health,

School of Medicine, Dentistry and Biomedical Sciences,

Queen's University Belfast, Royal Victoria Hospital, 274

Grosvenor Road, Belfast, BT12 6BA

${ }^{*}$ Correspondence to: Dr Mark Ide

Email: mark.ide@kcl.ac.uk

\section{Refereed Paper}

Accepted 2 October 2014

DOI: 10.1038/sj.bdj.2014.903

${ }^{\circledR}$ British Dental Journal 2014; 217: 467-474 sepsis and diseases of other organs of the body which he believed were caused by the dissemination of organisms or toxic products from the mouth. ${ }^{2}$ Hunter connected a large range of conditions with oral sepsis including gastro-intestinal problems, cirrhosis, rheumatoid arthritis and also vague symptoms such as debility, cardiac irregularity and neurasthenia. The majority of these associations were based on clinical reports of improvement after removal of the septic focus usually the teeth. ${ }^{2,3}$ The theory of focal infection gained much support from leaders of the dental profession, on both sides of the Atlantic, in the first half of the twentieth century. The theory was attractive as it improved the standing of dentists who could be considered to be working in concert with the medical profession to improve the health of their patients and coincided with a campaign in Britain to limit dentistry to those with qualifications. ${ }^{4}$

The views expressed in textbooks published well into the twentieth century were often heavily influenced by the theory of focal infection. Steadman ${ }^{5}$ described a series of cases which were treated by extractions in which the patients became better after they had all their teeth extracted. He stated that there was "little doubt that physical well being was affected adversely by the constant absorption of toxins from the mouth'. ${ }^{5}$ This and other similar texts, which were expressions of the clinical experience of the authors, were likely to have convinced students or dentists that that if they were in any doubt about the presence of an infected focus such as periodontal disease the affected teeth should be removed. The acceptance of the theory of focal infection resulted in wholesale removal of teeth in an attempt to treat a variety of conditions. Only 50 years ago in the United Kingdom it was the norm for the middle-aged and elderly to have no natural teeth. The first Adult Dental Health Survey of the UK in 1968 found that 71\% of those aged 55 or older were edentulous. ${ }^{6}$ This almost certainly represented a hangover from the approach taken in the first half of the twentieth century. There was a growing recognition that no controlled clinical studies supported the opinions of the proponents of focal infection and it was discarded. Seminal studies such as the demonstration of the central and causative role of dental plaque improved our understanding of the pathogenesis of dental diseases. ${ }^{7}$ In recent years there has been a shift towards disease prevention and a focus on maintaining a functional dentition throughout life.

It came as something of a surprise when reports started to emerge in the late 1980s and early 1990s from well-designed scientific studies of possible linkages between periodontal disease and other diseases..$^{8-11}$ Prospective cohort studies, which showed periodontal disease was associated with an increased risk of premature death from any cause, suggested the hypothesis that periodontitis could be a risk factor for other diseases. $^{9,12,13}$ There was an explosion in clinical research in this area and periodontal disease has been linked to a number of diseases and conditions that have a major impact on public health, including cardiovascular disease, adverse pregnancy outcomes, diabetes, respiratory disease, chronic kidney disease, rheumatoid arthritis, cognitive impairment, 
obesity, metabolic syndrome and cancer. ${ }^{14}$ Increasingly details of these putative relationships have entered the public domain through the popular press, television and particularly with the widespread availability of information on the Internet. Our patients are increasingly aware of research into possible links between gum disease and other diseases and may be concerned about the consequences for their personal health. On a population basis the question of whether or not periodontal disease increases the risk of other diseases is important given its high prevalence. The most recent Adult Dental Health Survey of the UK in 2009 reported that $66 \%$ of those aged 55 and above had periodontal attachment loss (PAL) over $4 \mathrm{~mm}$, while $21 \%$ had PAL over $6 \mathrm{~mm}$ which would equate to significant periodontal destruction. ${ }^{15}$ These levels are similar to other data gathered worldwide; for example, the 2009/2010 National Health and Nutrition Examination Survey cycle in the United States reported that 64\% of those aged 65 years and older had moderate or severe periodontitis. ${ }^{16}$ Such prevalence figures are high in comparison with other diseases and recently there has been a reappraisal suggesting that many epidemiological studies have underestimated the prevalence of periodontitis. ${ }^{15,16}$

Within the limitations of this review we will focus on two systemic outcomes that may be linked to periodontal disease, namely atherosclerotic cardiovascular disease and adverse pregnancy outcomes. We will critically appraise the evidence with a focus on systematic reviews and recent key scientific papers to provide the current state of science. We would emphasise that this is a rapidly changing field with data emerging every year.

\section{PERIODONTAL DISEASE AND ATHEROSCLEROTIC VASCULAR DISEASE}

\section{What is the evidence for any association?}

Studies in Finland have provided evidence of an association between poor dental health and acute myocardial infarction ${ }^{8}$ and between dental infection and coronary atherosclerosis in men. ${ }^{17}$ Subsequently epidemiological studies from the United States reported, after adjustment for known cardiovascular risk factors, that the risk of coronary heart disease was increased by between 50\% and 70\% in those with periodontitis. ${ }^{9} 10$ These early studies which highlighted possible linkages resulted in a large body of research work that investigated periodontitis as an independent risk factor for atherosclerosis including stroke ${ }^{18}$ and coronary heart disease. ${ }^{19-21}$ There were, however, wide variations in the definitions of periodontal exposure in various studies ranging from clinical or radiographic assessment of periodontal disease to applying surrogate measures such as tooth loss or self-reported diagnosis of periodontitis. Also cardiovascular disease was measured by different methods in different studies, some of which included self-reporting of a history of heart disease. An increased emphasis on systematic reviews has helped to address some of these issues and meta-analysis has been applied to produce estimates of any overall association. A meta-analysis by Bahekar et al. ${ }^{22}$ found that those with periodontal disease, assessed both clinically and by self-report, had a 14\% increased risk (relative risk $[R R]=1.14,95 \%$ CI 1.07-1.21) of fatal and non-fatal coronary artery disease. A further meta-analysis of cohort studies from the United States and Finland by Humphrey et al. ${ }^{23}$ reported that those with periodontal disease had a $24 \%$ increased risk $(\mathrm{RR}=1.24,95 \% \mathrm{CI} 1.01-1.51)$ for coronary heart disease or cardiovascular disease. This included studies which relied on self-report and these were more likely to misclassify periodontal disease than those which used a clinical examination. Such misclassification is non-differential, however, it does reduce the size of any observed association. ${ }^{24}$ When the meta-analysis was limited to studies which relied on a clinical examination to identify periodontitis the association was stronger RR $=1.39$ (95\% CI 1.19-1.62). ${ }^{23}$ Furthermore, if the follow-up for cardiovascular disease was increased to 15 years or more the relative risk was even higher 1.67 (95\% CI 1.27-2.20). ${ }^{23}$

There have been two recent major systematic reviews of a possible association between periodontal disease and atherosclerotic cardiovascular disease. The American Heart Association (AHA) comprehensively reviewed the evidence to date. ${ }^{25}$ They reported a higher risk of myocardial infarct related cardiovascular outcomes was associated with poorer periodontal status in studies which used a clinical periodontal assessment. ${ }^{25}$ This association was not found in other studies which relied on tooth loss as a surrogate measure to identify periodontal disease or used the self-reported presence of periodontal disease. ${ }^{25}$ The AHA concluded that studies supported an association between periodontal disease and atherosclerotic vascular disease independent of known confounders. ${ }^{25}$ The second major systematic review was by Dietrich et al. ${ }^{26}$ as part of the first joint workshop of the European Federation of Periodontology (EFP) and the American Association of Periodontology
(AAP). The systematic review was based on studies with clinical or radiographic assessment of periodontal disease. ${ }^{26}$ The outcome was incident disease where the periodontal exposure preceded the identification of cardiovascular disease. No meta-analysis was attempted because of the significant heterogeneity in the studies. It was concluded that current evidence supported the view that incident cardiovascular disease is higher in those with periodontal disease or worse periodontal status independent of major known cardiovascular risk factors. ${ }^{26}$

\section{What is the impact of common risk factors?}

Atherosclerotic cardiovascular disease is multifactorial involving genetic, environmental and lifestyle factors. Some of the traditional risk factors for cardiovascular disease are not amenable to change such as age and sex while others are modifiable such as dyslipidaemia, hypertension, smoking, body weight and composition and physical activity. Many of these cardiac risk factors have also been identified as risk factors for chronic periodontitis. It is therefore possible that associations between periodontal disease and cardiovascular disease could reflect confounding by shared risk factors. Confounding is distortion of the association between an exposure and an outcome brought about by the association of another factor with both the outcome and the exposure. ${ }^{27}$

Statistical techniques available to control for the effects of confounding factors are widely used in association studies. Most studies have been adjusted for obvious confounders. However, there may be residual confounding reflecting difficulty in controlling for all dimensions of particular factors. Smoking is the principal environmental risk factor for periodontitis and it has been estimated that over $50 \%$ of all cases of chronic periodontitis can be attributed to cigarette smoking. ${ }^{28}$ Smoking is also a major risk factor for cardiovascular disease and is likely, therefore, to be an important confounding factor in any putative association between periodontitis and cardiovascular disease. ${ }^{29}$ In any analysis there is likely to be residual confounding reflecting the difficulty in controlling for all aspects of the smoking history of study participants. We can restrict analysis to specific groups, for example, never smokers. However, this has drawbacks in that outcomes can only be applied to the specific group. In this context one study found a strong association between chronic periodontitis and acute myocardial infarction in never smokers. ${ }^{19}$ Nevertheless, confounding remains a challenging issue in 
the interpretation of the associations found between periodontal disease and atherosclerotic cardiovascular disease. ${ }^{30}$

Established cardiovascular risk factors do not completely explain the excess risk in those with periodontal disease. There may be unrecognised confounders, for example common genetic risk factors. The chromosomal region 9p21.3 contains a robust genetic marker of coronary heart disease ${ }^{31}$ which has also been associated with periodontitis $^{32,33}$ providing support for the idea that shared susceptibility genes might be involved in the pathogenesis of both conditions. No published studies have investigated whether genetic variability at this chromosomal locus could explain the link between periodontitis and atherosclerotic cardiovascular disease.

\section{What are the possible mechanisms?}

If periodontal disease has a link to cardiovascular disease then we need to understand how it could have a plausible role. Atherosclerosis is a condition in which the artery wall thickens as a result of the accumulation of calcium and fatty materials (atheroma) which form plaques and cause the affected arteries to harden (sclerosis). The most important clinical consequences of atherosclerosis arise in the coronary, carotid and cerebral arteries. Previously, atherosclerotic plaque formation was considered as a cholesterol storage disease related to high dietary fat intake, however, it is now accepted that inflammation has a prominent role. ${ }^{34-36}$

Bacteria, which are central to the pathogenesis of periodontitis, may provide a direct or indirect mechanistic link to the development or progression of atherosclerotic vascular disease. In severe periodontitis gram-negative anaerobic bacteria are present in large numbers with up to 100 million bacteria in one pocket related to one surface of one tooth. ${ }^{37}$ Frequent transient bacteraemias occur in patients with periodontal infections, when the highly vascular, chronically inflamed gum tissues are mechanically irritated by daily activities such as toothbrushing and chewing. ${ }^{38,39} \mathrm{An}$ increase in intensity of bacteraemias correlates with the extent and severity of periodontitis. ${ }^{40}$ Infectious agents, or endotoxin derived from gramnegative bacteria, could have direct effects in stimulating the development of atheromatous plaques. ${ }^{41}$ Periodontal bacteria have been detected in thrombi from patients with acute myocardial infarction raising the possibility that they could have a role in the instability and rupture of atheromatous plaques. ${ }^{42}$ The scientific evidence for periodontal bacteria as contributors to atherosclerosis has been comprehensively reviewed by Reyes et al. ${ }^{43}$
Alternatively periodontal bacteria or bacterial products could have indirect systemic effects by inducing the formation of acute phase proteins. C-Reactive protein (CRP) production is part of the non-specific acute phase response to most forms of inflammation, infection and tissue damage. ${ }^{44}$ Prospective epidemiological studies have demonstrated that CRP levels independently predict the risk of first coronary events..$^{45}$ In this context the clinical relevance of moderate increases in CRP, smaller than those associated with systemic infection, has been highlighted. ${ }^{46}$ There is strong evidence that CRP is elevated in periodontitis-affected subjects. ${ }^{47,48}$ It has been hypothesised that any association between periodontitis and cardiovascular disease could be due to the moderate increases in CRP reported in subjects with poor periodontal health. ${ }^{49}$ Further in-depth discussion of the inflammatory mechanisms which could link periodontitis and cardiovascular diseases, including those tested in animal models, are beyond the scope of this paper, however, these have been reviewed recently by Scheinken and Loos. ${ }^{50}$

\section{What are the effects of interventions?}

It has been shown that interventions which target well established risk factors for atherosclerosis, for example lowering LDL by reducing dietary fat intake or taking statins, translate into reductions in the likelihood of cardiovascular events. If periodontal disease is a risk factor for atherosclerotic cardiovascular disease then periodontal treatment could provide a method of reducing the risk of progression. No prospective studies have evaluated whether periodontal treatment prevents heart disease or has an effect on reducing clinical end-points such as myocardial infarction or stroke. ${ }^{25}$ This would require randomised, prospective clinical trials and the practical limitations are immense. The current standard of cardiovascular care is so successful that populations have low event rates and therefore trials investigating new strategies such as periodontal treatment would require very large numbers of participants and long study durations. ${ }^{35}$

One attempt has been made to address whether periodontal treatment could have a role in the secondary prevention of cardiovascular disease. ${ }^{51}$ Patients with a history of cardiovascular disease who also had periodontal disease were randomised to receive intensive periodontal treatment or to community standard care after being informed that they required periodontal treatment. ${ }^{51}$ There were no differences between the groups either in relation to their periodontal condition or to markers of systemic inflammation after
12 months. ${ }^{51}$ Many of those referred back for community care had received specialist periodontal treatment in the community, which would have been little different from the intervention being tested. ${ }^{51}$ This study highlighted the difficulties inherent in setting up a randomised trial of periodontal treatment to address the question of a possible role for periodontal disease in the progression of atherosclerotic cardiovascular disease.

Since clinical end-point studies seem to be particularly challenging, an alternative approach to investigate the effects of periodontal treatment on cardiovascular risk is to investigate the effects of periodontal treatment on surrogate markers of cardiovascular disease such as CRP or measures of endothelial function. ${ }^{35}$ The effects of periodontal treatment on biomarkers has been comprehensively reviewed by D'Aiuto et al. ${ }^{52}$ who noted that virtually all relevant trials were small in size and had limited follow-up, mainly for six months with only a few studies extending to one year. The periodontal treatment in the studies consisted of scaling and root planing completed under local anaesthesia. The review highlighted that there was no strong evidence, as would be provided by multiple high quality RCTs, of the effects of periodontal treatment. ${ }^{52}$ There was moderate evidence, as provided by one relevant high quality RCT, that periodontal treatment improves endothelial function and reduces CRP levels but does not reduce serum lipids. ${ }^{52,53}$ Endothelial function is a key regulator of vascular biology. Changes in the endothelium, termed endothelial dysfunction, herald atheroma formation. Tonetti et $a l .{ }^{53}$ have shown that periodontal treatment has a positive effect on endothelial function, which can still be demonstrated six months after treatment.

Periodontal treatment was consistently associated with transient amplification of the systemic inflammatory response in the first month following treatment. ${ }^{52}$ This is probably due to bacteria being forced into the blood stream during periodontal treatment ${ }^{38}$ or as a result of inflammation related to the mechanical effects of treatment. The implications are not fully understood but one study has reported a small increase in the risk of vascular events following invasive dental treatment. ${ }^{54}$ After one month there is evidence of a progressive improvement in markers of inflammation. A systematic review reported modest evidence of a reduction in CRP after periodontal treatment but that this did not occur in all studies. ${ }^{47}$

\section{Are further studies needed?}

The available information shows there is good evidence of an association between periodontal disease and the atherosclerotic 
vascular disease which is independent of known confounders. ${ }^{25,26}$ In addition there are plausible mechanisms which might explain this relationship, however, the key question is one of causality. Studies to date do not demonstrate a causative relationship between these conditions. ${ }^{55}$ In practical terms the question to be asked is: does treating periodontal disease affect the risk of future cardiovascular disease? The difficulties of ever providing a definitive answer to this question have been discussed earlier. Prospective cohort studies, based on samples from the general population, would be valuable, along with further studies of surrogate biomarkers, although interpreting these will always present further challenges particularly given the need to control for confounding variables.

\section{What should we tell our patients?}

Recently the Periodontitis and atherosclerotic disease: consensus report of the EFP/ AAP workshop on periodontitis and systemic diseases made recommendations for oral health practitioners. ${ }^{56}$ These recommendations are freely available from the Journal of Clinical Periodontology website and can be summarised briefly here:

- Dental practitioners should be aware of the evidence for periodontal disease as a risk factor for atherosclerotic disease and advise their patients of the risk

- It is recommended that periodontitis patients with other cardiovascular risk factors should be referred for a medical consultation

- Modifiable risk factors for periodontitis (and ACVD) should be addressed in the dental practice and in the context of comprehensive periodontal therapy for example, smoking cessation programmes and advice on lifestyle modifications (diet and exercise).

These recommendations are similar to those of the American Journal of Cardiology and Journal of Periodontology editors' consensus which suggested that dentists should inform patients with moderate to severe periodontitis that there may be an increased risk for cardiovascular disease associated with periodontitis. ${ }^{57}$ In this context periodontitis may act as a marker of disease in the same vein as has been identified for those who present with slightly elevated levels of CRP or mild hypertension. ${ }^{58}$

Atherosclerosis begins in early life. Post mortems of relatively young individuals who died from traumatic causes have shown that atherosclerosis is common. ${ }^{59}$ The absence of major established risk factors for atherosclerotic cardiovascular disease at 50 years of age translates into an $80-90 \%$ reduction in lifetime cardiovascular risk. ${ }^{59}$ It may be advantageous to focus on the early stages of life and ensure that any possible risk factors are reduced or eliminated ${ }^{59}$ and in this context the prevention or control of periodontal disease may be helpful. When this is highlighted to patients it may provide better opportunities and traction for preventive counselling and improved periodontal care in those who have high susceptibility to periodontal disease and are most likely to benefit. There is resonance with the finding of Dietrich et al. ${ }^{60}$ that all studies that stratified by age reported stronger associations between periodontal disease and coronary heart disease in younger subjects (those aged below 60 years).

\section{PERIODONTAL DISEASE \\ AND PREGNANCY OUTCOME}

One of the major potential links of interest between periodontal disease and systemic health has been in the field of pregnancy outcomes. Research in this field started in the USA in the mid-1990s, and has since spread globally, involving a range of populations and differing investigative approaches. However a consistent pattern of results confirming or refuting such a link has not been achieved.

The link between periodontal disease and pregnancy outcome was spurred by developments in medicine showing how inflammatory processes play an important role in pregnancy, especially towards the end of gestation, and may be central to the process of delivery. ${ }^{61,62}$

The relatively high rate of complications in the USA compared to other westernised countries led to a resurgence of interest in managing pregnancy complications, especially since it was largely unclear, with the exception of a previous history of such problems, what the major risk factors were. However, such problems are not rare in the UK - recent data ${ }^{63,64}$ show that around 7.5\% of deliveries in the UK are preterm: one of the higher scores for European countries, and that $6.8 \%$ are of low birth weight. These complications can be life changing for parents and child, and are costly to manage. ${ }^{65,66}$

Hence the concept that simple interventions such as improved oral health could affect pregnancy outcome became a highly attractive possible way to improve overall health outcomes. The main pregnancy complications associated with maternal periodontal disease are low birth weight, preterm delivery, pre-eclampsia, still birth and combinations of these. Low birth weight is defined by the World Health Organisation as the weight of an infant at birth of less than 2,500 grams ( 5.5 pounds), irrespective of the gestational age of the infant. ${ }^{67}$ The WHO has defined preterm birth ${ }^{68}$ in different categories:

- Extremely preterm: less than 28 weeks

- Very preterm: 28 to 32 weeks

- Moderate to late preterm 32 to 37 weeks.

Pre-eclampsia affects up to five percent of pregnancies in the UK, ${ }^{69}$ and about $10 \%$ of all pregnancies worldwide. ${ }^{70}$ It is diagnosed based on development of sustained hypertension after 20 weeks gestation associated with proteinuria, and can have severe, potentially fatal, consequences for mother and baby. In 2012, the stillbirth rate in England was 4.9 per 1,000 births. ${ }^{71}$ North east England had the lowest stillbirth rate with 3.8 stillbirths per 1,000 births, whereas London had the highest stillbirth rate at 5.7 per 1,000 births. $^{72}$

\section{THE ASSOCIATION BETWEEN PERIODONTITIS AND PREGNANCY OUTCOME}

Many studies have been published investigating possible associations between maternal periodontal disease and subsequent pregnancy outcome. These have followed a range of designs, from retrospective case control to longitudinal cohort studies, with oral health being assessed in several differing ways. This, together with the wide range of groups studied, may explain at least partly why these studies have not generally all come to the same conclusions regarding possible associations. ${ }^{11,73-78}$ A further complicating factor is one of confounders - environmental, lifestyle or other factors which may increase the risk not only of gum disease but also of poor pregnancy outcome. A typical example of these would be smoking, ${ }^{29}$ and not all studies have adequately controlled for this in their designs or analyses. ${ }^{79}$

As a result the approach of carrying out a systematic review, where studies are rated and included based on strict, pre-defined quality criteria, would appear to be a way to compensate for this. Several systematic reviews have been carried out in this field, the most recent being part of a joint European Federation of Periodontology and American Academy of Periodontology initiative to establish the current state of knowledge in this and associated fields. ${ }^{80}$ These have led to the conclusion that a modest association appears to exist between maternal periodontitis and the outcomes of low birth weight, preterm birth and pre-eclampsia. However, the strength of any observed observation may be considerably influenced by the study design employed by the investigators. 


\section{POTENTIAL MECHANISMS - INFLAMMATION AND PREGNANCY OUTCOME}

The last 20 years have seen a rapid increase in our knowledge of changes seen during pregnancy and delivery, even though the true risk picture for these complications is not fully clear. It is now believed that there are steady changes in circulating levels of proinflammatory markers during pregnancy, and that these peak around the time of delivery. During a normal pregnancy, there are elevations in tumour necrosis factor-alpha (TNF- $\alpha$ ), prostaglandins (such as $\mathrm{PGE}_{2}$ ) and CRP. ${ }^{81-85}$

In addition, various studies using human data and animal models have clarified how infection may impact pregnancy. It is known that inflammation of the foetal membranes (chorioamnionitis), which can occur following local bacterial shifts or infection in the birth canal towards an anaerobic flora, ${ }^{86-88}$ is associated with elevated levels locally of interleukins $-1 \alpha$ and $-1 \beta$, premature delivery and low birth weight. ${ }^{89-94}$ This is especially true if there has been premature rupture of membranes. However, other human studies have shown that not all women with infected amniotic fluid have ruptured membranes. ${ }^{95}$ Studies also have shown that exposure to periodontal 'pathogens' or endotoxin administered in remote sites to pregnant animals is followed by release of proinflammatory markers such as TNF- $\alpha$, interleukins and $\mathrm{PGE}_{2}$, within the placenta ${ }^{94,96,97}$ and even by the foetus. ${ }^{98}$ These in turn can induce rupture of membranes, cervical dilation and uterine contraction..$^{99}$ The picture was completed by the publication of results showing that otherwise asymptomatic women who delivered before 35 weeks were found to have raised levels of these markers in their amniotic fluid..$^{100,101}$ Hence it would appear that the pre-existing inflammatory pathway normally used for induction of delivery at term may in fact be modified and upregulated by the presence of local infection and local or systemic inflammatory changes, resulting in premature rupture of membranes, preterm delivery or compromised foetal growth.

There are several ways by which periodontal infection could impact on pregnancy outcome, either relying on systemic effects of periodontal changes, or as a result of oral bacteria having spread systemically, possibly within the circulation. Each of these has been supported based on animal models or on observational data in vitro and in vivo. ${ }^{102}$

\section{POTENTIAL MECHANISMS - SYSTEMIC INFLAMMATION OR BACTERAEMIA FROM ORAL INFECTION, OR BOTH?}

As outlined above, it has been established that the presence of periodontitis is associated with an elevation in circulating levels of proinflammatory molecules such as CRP. ${ }^{47}$ In addition it would appear that although an episode of periodontal treatment, such as effective subgingival instrumentation, may cause a short term elevation in these for a few days following treatment; this is followed by a reduction in levels of proinflammatory molecules..$^{52,103-105}$ This has been supported by the observation that the removal of all teeth in a terminal dentition has been shown to be followed by a reduction in levels of proinflammatory markers. ${ }^{106,107}$ These markers may originate either locally from periodontal tissues (as a part of bacterially-stimulated local inflammation), or more likely largely from other organs such as the liver and adipocytes throughout the body.

Although such a change has been attributed to mechanical effects of periodontal treatment, this does not explain why there are longer-term changes in these markers following successful periodontal therapy. A range of studies have suggested that in fact the elevated levels of markers seen in periodontal patients are more likely to be a reflection of repeated long term low grade systemic exposures to oral bacteria. These are thought to be initiated either by events such as chewing or toothbrushing, both of which are known to result in bacteraemia and the introduction of bacterial toxins into the bloodstream..$^{38-40,108}$ More recent work has suggested that in fact some of the organisms often found in diseased periodontal sites, such as Fusobacterium nucleatum, Porphyromonas gingivalis and Campylobacter rectus, are especially good at selectively colonising certain remote organs such as the placenta following bacteraemia in animal models. ${ }^{109,10}$ These then have the potential to initiate the changes outlined above. These processes are reviewed well by Madianos et al. ${ }^{110}$

\section{HOW DOES THIS RELATE TO PREGNANCY OUTCOME?}

While there are plausible mechanisms supporting possible impacts of periodontal disease on pregnancy outcome, and supportive data from human and animal studies, this should be validated by clinical studies showing whether such a linkage can be demonstrated (association: maternal periodontal disease can be linked to adverse pregnancy outcome), and if this link is causative. The best way to prove the latter would be to show that successful treatment of periodontal disease in pregnant women reduced the risk of adverse pregnancy outcome.

\section{DOES THIS MEAN THAT TREATMENT HELPS REDUCE RISK?}

The study of associations between periodontal health and pregnancy outcome have also been accompanied by various investigations of the effectiveness of periodontal treatment in improving pregnancy outcome. Again, studies of varying size and quality have been carried out in a range of geographical locations, and these have not all reported the same pattern of results. While it has been established that periodontal treatment in pregnancy can improve oral health ${ }^{111,112}$ and be matched by beneficial changes in oral microbiological status, ${ }^{113}$ the majority of large well executed studies have failed to show any effect of nonsurgical periodontal treatment on the incidence of adverse pregnancy outcomes, ${ }^{112-117}$ and this has been supported by systematic reviews. ${ }^{118,119}$

It is unclear why treatment has failed to show improvements even though other data suggest that it may be expected to do so. This anomaly may be related to the effects of confounders as outlined above, or to the fact in some studies it was not possible to obtain what the authors called 'complete periodontal health. ${ }^{112}$ It may be difficult to successfully carry out an intervention study in this group, who are subjected to many conflicting demands at the same time. It has also been suggested that in fact periodontal exposure in early pregnancy (before any such intervention has been attempted) may be the initiating event, or that only intense marginal inflammation, as is seen in pregnancy gingivitis, is required. ${ }^{110}$ Finally some workers have suggested that there may be individual variation in the progression and intensity of pregnancy gingivitis, and that this may reflect an underlying inflammatory susceptibility which could also be reflected by increased chorioamnionitis and inflammation, as outlined above. ${ }^{120}$

\section{COULD PERIODONTAL TREATMENT DURING PREGNANCY MAKE THINGS WORSE?}

As described above, it appears that there is a short term elevation in systemic inflammatory status after root surface instrumentation, and in some cases this may even lead to a low grade pyrexial response. ${ }^{121}$ This leads to the possibility that intensive periodontal treatment may cause a sufficiently intense inflammatory challenge to compromise pregnancy outcome. However, there have now been a number of well-organised and thoroughly documented clinical trials of periodontal treatment during pregnancy completed and published. None of these papers have described an increased incidence of adverse pregnancy outcome as a consequence of periodontal treatment. This tends to suggest that treatment would be safe to carry out during pregnancy. However, if one were concerned especially with a high risk 
patient, it may be wise to consider regular intensive oral hygiene instruction and thorough supragingival scaling as an alternative to episodes of subgingival instrumentation during pregnancy. Such an approach has been shown to be effective in promoting periodontal health and stability ${ }^{122}$ and offers a less concentrated treatment approach, at least during pregnancy, while still improving oral hygiene, reducing gingival inflammation and the possible risk of bacteraemia challenges.

\section{PERIODONTITIS AND PREGNANCY OUTCOME: RECOMMENDATIONS FOR PRACTITIONERS AND PATIENTS}

The most important message for dental practitioners to pass on to pregnant patients is that, based on current data and our present understanding of the supporting science, nonsurgical periodontal treatment is believed to be safe and effective during pregnancy. In addition, the widely recognised risk of increased marginal inflammation related to hormonal changes during pregnancy ('pregnancy gingivitis') should be prevented or controlled if possible by encouraging good self-performed plaque control, supported by professional instrumentation and review where necessary.

While there are data supporting potential mechanisms for recognised associations between maternal periodontal disease and adverse pregnancy outcome, clinical intervention studies have thus far failed to illustrate that periodontal treatment in pregnancy can reduce the risk of adverse pregnancy outcome. However, delivering such treatment is not, as described above, likely to cause harm (the practitioner can always deliver the most basic of maintenance care if there are concerns expressed by the patient) and is likely to help improve oral health and wellbeing during pregnancy.

\section{CONCLUSIONS}

A possible linkage between periodontal disease and other diseases remains an intriguing concept. While there is good evidence that periodontal disease is an independent risk factor for various systemic diseases and conditions, as shown by the review of links with cardiovascular disease and adverse pregnancy outcomes, the evidence currently falls short of support for a causative role. ${ }^{25,26,55,120}$ To date the strength of any associations have been shown to be modest. $^{22,23,30,55,120}$ There are plausible mechanisms, however, clinical intervention studies have not provided definitive guidance. There is still considerable ongoing work in this field acknowledging that we do not yet fully understand the big picture of what may or may not be going on. It is important that dentists keep up to date with current research into this question so that they are in a position to provide relevant advice to their patients. ${ }^{56}$ Further information is available at the websites of the British Society of Periodontology, the European Federation of Periodontology and the American Academy of Periodontology, with an emphasis on the recent joint workshop:

- EuroPerio8: http://www.efp.org/ europerio/europerio8/

- British Society of Periodontology: http://www.bsperio.org.uk/

- American Academy of Periodontology: http://www.perio.org/

- European Federation of Periodontology: http://www.efp.org/

- EFP workshops: http://perioworkshop. efp.org/

- Joint EFP/AAP workshop proceedings (available for free to all) http:// onlinelibrary.wiley.com/doi/10.1111/ jcpe.2013.40.issue-s14/issuetoc.

1. Prinz H. Dental chronology: a record of the more important events in the evolution of dentistry, 1st ed. London: Henry Kimpton, 1945.

2. Newman H. Focal Infection. J Dent Res 1996; 75: 1912-1919.

3. Alldritt S. Pyorrhoea. Inaugural address. New Lecture Series. Belfast: Queen's University, 1966.

4. Dussault G, Sheiham A. The theory of focal sepsis and dentistry in early twentieth century Britain. Soc Sci Med 1982; 16: 1405-1412.

5. Steadman F. Pyorrhoea alveolaris, 2nd ed. London: Henry Kimpton, 1927.

6. Grey P, Todd J, Slack G, Bulman J. Adult dental health in England and Wales in 1968. London: Her Majesty's Stationery Office, 1970.

7. Loe $H_{1}$ Theilade $E$, Jensen $S B$. Experimental gingivitis in man. J Periodontol 1965; 36: 177-187.

8. Mattila K J, Nieminen M S, Valtonen V V et al. Association between dental health and acute myocardial infarction. Br Med J 1989; 298: 779-781.

9. Destefano F, Anda R F, Kahn H S, Williamson D F, Russell C M. Dental disease and risk of coronary heart disease and mortality. Br Med J 1993; 306: 688-691.

10. Beck J, Garcia R, Heiss G, Vokonas PS, Offenbacher S. Periodontal disease and cardiovascular disease. J Periodontol 1996; 67: 1123-1137.

11. Offenbacher $S$, Katz V, Fertik $G$ et al. Periodontal infection as a possible risk factor for preterm low birth weight. J Periodontol 1996; 67: 1103-1113.

12. Garcia R I, Krall E A, Vokonas P S. Periodontal disease and mortality from all causes in the VA Dental Longitudinal Study. Ann Periodontol 1998; 3: 339-349.

13. Linden $G J$, Linden $K$, Yarnell J, Evans $A$, Kee F, Patterson C C. All-cause mortality and periodontitis in 6070year-old men: a prospective cohort study. J Clin Periodontol 2012; 39: 940-946.

14. Linden G J, Lyons A, Scannapieco F A. Periodontal systemic associations: review of the evidence. J Clin Periodontol 2013; 40: S8-S19.

15. White D, Pitts N, Steele J, Sadler K, Chadwick B. Disease and related disorders-a report from the Adult Dental Health Survey 2009. Available at: http://www.hscic.gov.uk/catalogue/PUB01086/ aduldenthealsurvsummthemthe22009rep4.pdf (accessed 2 June 2014).

16. Eke P I, Dye B A, Wei L, Thornton-Evans G O, Genco $R \mathrm{~J}$. Prevalence of periodontitis in adults in the United States: 2009 and 2010. J Dent Res 2012; 91 : 914-920.

17. Mattila K J, Valle M S, Nieminen M S, Valtonen VV,
Hietaniemi K L. Dental infections and coronary atherosclerosis. Atherosclerosis 1993; 103: 205-211.

18. Wu T J, Trevisan M, Genco R J, Dorn J P, Falkner $\mathrm{K}$, Sempos C T. Periodontal disease and risk of cerebrovascular disease - The First National Health and Nutrition Examination Survey and its follow-up study. Arch Intern Med 2000; 160: 2749-2755.

19. Persson G R, Ohlsson A, Pettersson T, Renvert S. Chronic periodontitis, a significant relationship with acute myocardial infarction. Eur Heart J 2003; 24: 2108-2115.

20. Montebugnoli L, Servidio D, Miaton R A, Prati C, Tricoci P, Melloni C. Poor oral health is associated with coronary heart disease and elevated systemic inflammatory and haemostatic factors. J Clin Periodontol 2004; 31: 25-29.

21. Briggs J E, McKeown P P, Crawford V L et al. Angiographically confirmed coronary heart disease and periodontal disease in middle-aged males. J Periodontol 2006: 77: 95-102.

22. Bahekar A A, Singh S, Saha S, Molnar J, Arora R. The prevalence and incidence of coronary heart disease is significantly increased in periodontitis: A metaanalysis. Am Heart J 2007; 154: 830-837.

23. Humphrey L L, Fu R, Buckley D I, Freeman M, Helfand M. Periodontal disease and coronary heart disease incidence: A systematic review and metaanalysis. J Gen Intern Med 2008; 23: 2079-2086.

24. Dietrich T, Garcia R I. Associations between periodontal disease and systemic disease: Evaluating the strength of the evidence. J Periodontol 2005; 76: 2175-2184.

25. Lockhart P B, Bolger A F, Papapanou P N et al. Periodontal disease and atherosclerotic vascular disease: Does the evidence support an independent association? A scientific statement from the American Heart Association. Circulation 2012; 125: 2520-2544.

26. Dietrich T, Sharma P, Walter $C$, Weston P, Beck J. The epidemiological evidence behind the association between periodontitis and incident atherosclerotic cardiovascular disease. J Clin Periodonto/ 2013; 40: S70-S84.

27. Elwood M. Clinical appraisal of epidemiological studies and clinical trials, $3^{\text {rd }}$ ed. Oxford: Oxford University Press, 2007.

28. Tomar S L, Asma S. Smoking attributable periodontitis in the United States: findings from NHANES III. J Periodontol 2000; 71: 743-751.

29. Hujoel P P, Drangsholt M, Spiekerman C, DeRouen T A. Periodontitis systemic disease associations in the presence of smoking causal or coincidental? Periodontol 2000 2002; 30: 51-60.

30. Kebschull M, Demmer R T, Papapanou PN. 'Gum bug, leave my heart alone!' Epidemiologic and mechanistic evidence linking periodontal infections and atherosclerosis. J Dent Res 2010; 89: 879-902.

31. Samani N J, Erdmann J, Hall A S et al. Genomewide association analysis of coronary artery disease. New Eng J Med 2007; 357: 443-453.

32. Schaefer A S, Richter G M, Groessner-Schreiber B et al. Identification of a shared genetic susceptibility locus for coronary heart disease and periodontitis. PLOS Genetics 2009; 5: e1000378.

33. Ernst F D, Uhr K, Teumer, A et al. Replication of the association of chromosomal region 9p21.3 with generalized aggressive periodontitis (gAgP) using an independent case-control cohort. BMC Med Genet 2010; 11: 119.

34. Libby P. Inflammation in atherosclerosis. Nature 2002; 420: 868-874.

35. Libby P, Ridker P M, Hansson G K. Progress and challenges in translating the biology of atherosclerosis. Nature 2011; 473: 317-325.

36. Hansson GK. Mechanisms of disease Inflammation, atherosclerosis, and coronary artery disease. New Engl J Med 2005; 352: 1685-1695.

37. Pihlstrom B L, Michalowicz B S, Johnson N W. Periodontal diseases. Lancet 2005; 366: 1809-1820.

38. Forner L, Larsen $T$, Kilian M, Holmstrup P. Incidence of bacteraemia after chewing, toothbrushing and scaling in individuals with periodontal inflammation. J Clin Periodontol 2006; 33: 401-407.

39. Tomas I, Diz P, Tobias A, Scully C, Donos N. Periodontal health status and bacteraemia from 
daily oral activities: systematic review/meta-analysis. J Clin Periodonto/ 2012; 39: 213-228.

40. Geerts S O, Nys M, De M P et al. Systemic release of endotoxins induced by gentle mastication: association with periodontitis severity. J Periodonto/ 2002 73: 73-78.

41. Koren 0, Spor A, Felin J et al. Human oral, gut, and plaque microbiota in patients with atherosclerosis. $P$ Natl Acad Sci U S A 2011; 108: 4592-4598.

42. Ohki T, Itabashi Y, Kohno T et al. Detection of periodontal bacteria in thrombi of patients with acute myocardial infarction by polymerase chain reaction. Am Heart J 2012; 154: 164-167.

43. Reyes L, Herrera D, Kozarov E, Roldan S, ProgulskeFox A. Periodontal bacterial invasion and infection: contribution to atherosclerotic pathology. J Clin Periodontol 2013; 40: S30-S50.

44. Pepys M B, Hirschfield GM. C-reactive protein: a critical update. J Clin Invest 2003; 111: 1805-1812.

45. Danesh J, Wheeler J G, Hirschfield G M et al. C-reactive protein and other circulating markers of inflammation in the prediction of coronary heart disease. New Eng/ J Med 2004; 350: 1387-1397.

46. Pearson T A, Mensah G.A, Alexander R W et al. Markers of inflammation and cardiovascular disease: application to clinical and public health practice: A statement for healthcare professionals from the Centers for Disease Control and Prevention and the American Heart Association. Circulation 2003; 107: 499-511.

47. Paraskevas S, Huizinga J D, Loos BG. A systematic review and meta-analyses on C-reactive protein in relation to periodontitis. J Clin Periodontol 2008; 35: 277-290.

48. Linden G J, McClean K, Young I, Evans A, Kee F. Persistently raised $C$-reactive protein levels are associated with advanced periodontal disease. J Clin Periodontol 2008; 35: 741-747.

49. D'Aiuto F, Ready D, Tonetti M S. Periodontal disease and C-reactive protein-associated cardiovascular risk. J Periodontal Res 2004: 39: 236-241.

50. Schenkein H A, Loos B G. Inflammatory mechanisms linking periodontal diseases to cardiovascular diseases. J Clin Periodontol 2013; 40: S51-S69.

51. Offenbacher $S$, Beck J D, Moss K et al. Results from the periodontitis and vascular events (PAVE) study: A pilot multicentreed, randomized, controlled trial to study effects of periodontal therapy in a secondary prevention model of cardiovascular disease. J Periodontol 2009; 80: 190-201.

52. D'Aiuto F, Orlandi M, Gunsolley J C. Evidence that periodontal treatment improves biomarkers and CVD outcomes. J Clin Periodontol 2013; 40: S85-S105.

53. Tonetti MS, D'Aiuto F, Nibali L et al. Treatment of periodontitis and endothelial function. New Engl J Med 2007; 356: 911-920.

54. Minassian C, D'Aiuto F, Hingorani A D, Smeeth L. Invasive dental treatment and risk for vascular events. A self-controlled case series. Ann Intern Med 2010; 153: 499-506.

55. Linden G J, Herzberg M C. Periodontitis and systemic diseases: a record of discussions of working group 4 of the Joint EFP/AAP Workshop on Periodontitis and Systemic Diseases. J Clin Periodonto/ 2013; 40: S20-S23.

56. Tonetti M S, Van Dyke TE. Periodontitis and atherosclerotic cardiovascular disease: consensus report of the Joint EFP/AAP Workshop on Periodontitis and Systemic Diseases. J Clin Periodontol 2013; 40: S24-S29.

57. Friedewald V E, Kornman K S, Beck J D et al. The American Journal of Cardiology and Journal of Periodontology Editors' Consensus: Periodontitis and atherosclerotic cardiovascular disease. J Periodontol 2009; 80: 1021-1032.

58. Borgnakke W S, Glick M, Genco R J. Periodontitis The canary in the coal mine. J Am Dent Assoc 2013; 144: 764-766.

59. McGill H C, McMahan A, Gidding S S. Preventing heart disease in the 21 st century implications of the pathobiological determinants of atherosclerosis in youth (PDAY) study. Circulation 2008; 117: 1216-1227.

60. Dietrich T, Jimenez M, Kaye E A K, Vokonas PS, Garcia R I. Age-dependent associations between chronic periodontitis/edentulism and risk of coronary heart disease. Circulation 2008; 117: 1668-1674.

61. Fuchs $A$ R, Fuchs F. Endocrinology of human parturition: a review. Br J Obstet Gynaecol 1984; 91: 948-967.

62. De Meeus J B, Pourrat O, Gombert J, Magnin G. C-reactive protein levels at the onset of labour and at day 3 post-partum in normal pregnancy. Clin Exp Obstet Gynecol 1998; 25: 9-11.

63. OECD iLibrary. Infant health: Iow birth weight. In: Health at a glance: Europe 2012. OECD Publishing, 2012. Available at: http://dx.doi. org/10.1787/9789264183896-12-en (accessed October 2014)

64. MacDorman M F, Mathews T J. Percentage of preterm births, United States and selected European countries, 2004. Birth 2010; 37: 168

65. McCormick M C. The contribution of low birth weight to infant mortality and childhood morbidity. New Eng/ J Med 1985; 312: 82-90.

66. Costeloe K L, Hennessy E M, Haider S, Stacey F, Marlow N, Draper E S. Short-term outcomes after extreme pre-term birth in England, Comparison of two birth cohorts in 1995 and 2006 (the EPICure studies). BMJ 2012; 345: e7976.

67. Wardlow T, Blanc A, Zupan J, Ahman E. Low birthweight: country, regional and global estimates. UNICEF/WHO, New York/Geneva, 2004.

68. Blencowe $\mathrm{H}$, Cousens $\mathrm{S}$, Oestergaard $\mathrm{M}$ et al. National, regional and worldwide estimates of preterm birth. Lancet 2012; 379: 2162-2172.

69. NHS Choices. Pre-eclampsia. London, 2013 Available at: http://www.nhs.uk/conditions/Pre-eclampsia/ Pages/Introduction.aspx (accessed October 2014)

70. World Health Organization. WHO Recommendations for prevention and treatment of pre-eclampsia and eclampsia. Geneva: WHO, 2011

71. Office for National Statistics. Characteristics of live birth 1, England and Wales 2012. London: ONS, 2013.

72. Office for National Statistics. Death registration summary table. England and Wales 2012. London ONS, 2013.

73. Moore $\mathrm{S}$, Ide $\mathrm{M}$, Coward $\mathrm{PY}$ et al. A prospective study to investigate the relationship between periodontal disease and adverse pregnancy outcome. $\mathrm{Br}$ Dent J 2004; 197: 251-258.

74. Moore S, Randhawa M, Ide M. A case-control study to investigate an association between adverse pregnancy outcome and periodontal disease. J Clin Periodontol 2005; 32: 1-5.

75. Lopez N J, Smith P C, Gutierrez J. Higher risk of preterm birth and low birth weight in women with periodontal disease. J Dent Res 2002; 81: 58-63.

76. Davenport E S, Williams C E, Sterne J A, Murad S, Sivapathasundram V, Curtis M A. Maternal periodontal disease and preterm low birthweight: case-control study. J Dent Res 2002; 81: 313-318.

77. Farrell $\mathrm{S}$, Ide $\mathrm{M}$, Wilson $\mathrm{R}$ F. The relationship between maternal periodontitis, adverse pregnancy outcome and miscarriage in never smokers. J Clin Periodontol 2006: 33: 115-120.

78. Ide M, Farrell S. Associations between maternal periodontitis, periodontal treatment and pregnancy complications - Part 2: Analytical epidemiology. Perio 2005; 3: 173-182.

79. Hujoel P P, Lydon-Rochelle M, Robertson P B, De Aguila M A. Cessation of periodontal care during pregnancy: effect on infant birthweight. Eur J Oral Sci 2006; 114: 2-7.

80. Ide M, Papapanou P N. Epidemiological evidence for associations between maternal periodontal disease and adverse pregnancy outcomes - a systematic review. J Periodontol 2013; 84: 181-194.

81. Drife J O, Calder A A. Prostaglandins and the uterus. Oxford: Springer Verlag, 1992

82. Hillier S L, Witkin S S, Krohn M A, Watts D H, Kiviat $N B$, Eschenbach $D A$. The relationship of amniotic fluid cytokines and preterm delivery, amniotic fluid Infection, histologic chorioamnionitis, and chorioamnion infection. Obstet Gynecol 1993; 81: 941-948.

83. Romero R, Baumann P, Gonzalez R et al. Amniotic fluid prostanoid concentrations increase early during the course of spontaneous labour at term. Am
Obstet Gynecol 1994; 171: 1613-1620.

84. O'Brien W F. The role of prostaglandins in labour and delivery. Clin Perinatol 1995: 22: 973-984.

85. Larsson A, Palm M, Hansson L O, Basu S, Axelsson 0 . Reference values for alpha(1)-acid glycoprotein, alpha(1)-antitrypsin, albumin, haptoglobin, C-reactive protein, $\lg \mathrm{A}, \lg \mathrm{G}$ and $\lg \mathrm{M}$ during pregnancy. Acta Obstet Gynecol Scand 2008; 87: 1084-1088.

86. Gibbs R S, Romero R, Hillier S L, Eschenbach D A Sweet $R$ L. A review of premature birth and subclinical infection. Am J Obstet Gynecol 1992; 166: 1515-1528.

87. Hill G B. Preterm birth: associations with genital and possibly oral microflora. Ann Periodontol 1998; 3: 222-232.

88. Gibbs R S, Davies J K, McDuffie R S et al. Chronic intrauterine infection and inflammation in the preterm rabbit, despite antibiotic therapy. Am J Obstet Gynecol 2002: 186: 234-239.

89. Hillier S L, Martius J, Krohn M, Kiviat N, Holmes K K Eschenbach D A. A case control study of chorioamniotic infection and histologic chorioamnionitis in pregnancy. New Engl J Med 1993; 319: 972-978.

90. Romero R, Brody D T, Oyarzun E et al. Infection and labour III. Interleukin-1: a signal for the onset of parturition. Am J Obstet Gynecol 1989a; 160: 1117-1123.

91. Romero R, Manogue K R, Mitchell M D et al. Infection and labour. IV. Cachectin-tumor necrosis factor in the amniotic fluid of women with intraam niotic infection and preterm labour. Am J Obstet Gynecol 1989; 161: 336-341.

92. Romero R, Mazor M, Sepulveda W, Avila C, Copeland $D$, Williams J. Tumour necrosis factor in preterm and term labour. Am J Obstet Gynecol 1992; 166: 1576-1587.

93. Romero R, Gomez R, Ghezzi F et al. A fetal systemic inflammatory response is followed by spontaneous onset of preterm parturition. Am J Obstet Gynecol 1998: 179: 193-186.

94. Fidel $P$ L Jr., Romero R, Wolf N, Cutright J, Ramirez M, Araneda H C. Systemic and local cytokine profiles in endotoxin-induced preterm parturition in mice. Am J Obstet Gynecol 1994: 170: 1467-1475.

95. Andrews W W, Hauth J C, Goldenberg R L, Gomez R, Romero R, Cassell G H. Amniotic fluid interleukin-6: correlation with upper genital tract microbial colonization and gestational age in women delivered after spontaneous labour versus indicated delivery. Am J Obstet Gynecol 1995; 173: 606-612.

96. Lopez B A, Watson S P, Phaneuf S, Europe-Finner $G$ N. Biochemistry and physiology of preterm labour and delivery Baillieres Clin Obstet Gynaecol 1993; 7: 523-552.

97. Collins J G, Smith M A, Arnold R R, Offenbacher S. Effects of Escherichia coli and Porphyromonas gingivalis lipopolysaccharide on pregnancy outcome in the golden hamster. Infect Immun 1994; 62: 4652-4655.

98. Dudley D J, Chen C L, Branch D W, Hammond E, Mitchell M D. A murine model of preterm labour: inflammatory mediators regulate the production of prostaglandin $\mathrm{E}_{2}$ and interleukin- 6 by murine deciduas. Biol Reprod 1993; 48: 33-39.

99. Chaouat G, Menu E, Clark D A, Dy M, Minowski M, Wegmann T G. Control of fetal survival in CBAX $\mathrm{DBA} / 2$ mice by lymphokine therapy. J Reprod Fert 1990; 89: 447-458

100. Ohno Y, Kasugai M, Kurauchi O, Mizutani S, Tomoda Y. Effect of interleukin 2 on the production of progesterone and prostaglandin E2 in human fetal membranes and its consequences for preterm uterine contractions. Eur J Endocrinol 1994; 130: 478-484.

101. Foulon W, Van Liedekerke D, Demanet C, Decatte L, Dewaele $M$, Naessens A. Markers of infection and their relationship to preterm delivery. Am J Perinatol 1995; 12: 208-211.

102. Farrell S, Ide M. Associations between maternal periodontitis, periodontal treatment and pregnancy complicationsPart 1: Potential pathogenic mechanisms and risk factors. Perio 2005; 3: 159-171.

103. D'Aiuto F, Nibali L, Mohamed-Ali V, Vallance $\mathrm{P}$, Tonetti M S. Periodontal therapy: a novel 
nondruginduced experimental model to study human inflammation. J Periodontal Res 2004; 39: 294-299.

104. Hussain Bokhari S A, Khan A A, Tatakis D N, Azhar M, Hanif M, Izhar M. Non-surgical periodontal therapy lowers serum inflammatory markers: a pilot study. J Periodontol 2009; 80: 1574-1580.

105. Graziani F, Cei S, Tonetti M et al. Systemic inflammation following non-surgical and surgical periodontal therapy. J Clin Periodontol 2010; 37: 848-854.

106. Rahman A U, Rashid S, Noon R et al. Prospective evaluation of the systemic inflammatory marker C-reactive protein in patients with end-stage periodontitis getting teeth replaced with dental implants: a pilot investigation. Clin Oral Impl Res 2005; 16: 128-131.

107. Taylor B A, Tofler G H, Carey H M R et al. Full mouth tooth extraction lowers systemic inflammatory and thrombotic markers of cardiovascular risk. J Dent Res 2006; 85: 74-78.

108. Ide $M$, Jagdev D, Coward PY, Crook M, Barclay G R, Wilson R F. The short-term effects of treatment of chronic periodontitis on circulating levels of endotoxin, C-reactive protein, tumour necrosis factor-alpha, and interleukin-6. J Periodonto/ 2004; 75: 420-428.

109. Han Y W, Redline R W, Li M, Yin L, Hill G B, McCormick T S Fusobacterium nucleatum induces premature and term stillbirths in pregnant mice: implication of oral bacteria in preterm birth. Infect Immun 2004; 72: 2272-2279.

110. Madianos P N, Bobetsis Y A, Offenbacher S. Adverse pregnancy outcomes (APOs) and periodontal disease: pathogenic mechanisms. J Clin Periodontol 2013; 40: S170-S180.

111. Michalowicz B S, Novak M J, Hodges I S et al. Serum inflammatory mediators in pregnancy: Changes after periodontal treatment and association with pregnancy outcomes. J Periodontol 2009; 80: 1731-1741.

112. Offenbacher $S$, Beck J D, Jared $H$ L et al. Effects of periodontal therapy on rate of preterm delivery: $A$ randomized controlled trial. Obstet Gynecol 2009; 114: $551-559$

113. Novak M J, Novak K F, Hodges J S et al. Periodontal bacterial profiles in pregnant women: Response to treatment and associations with birth outcomes in the obstetrics and periodontal therapy (OPT) Study. J Periodontol 2008; 79: 1870-1879.

114. Michalowicz B S, Hodges J S, DiAngelis A J et al. Treatment of periodontal disease and the risk of preterm birth. N Eng J Med 2006; 355: 1885-1894.

115. Newnham J P, Newnham I A, Ball C M et al. Treatment of periodontal disease during pregnancy: a randomized controlled trial. Obstet Gynecol 2009 114: $1239-1248$

116. Oliveira A M, de Oliveira P A, Cota L O, Magalhaes
C S, Moreira A N, Costa F 0. Periodontal therapy and risk for adverse pregnancy outcomes. Clin Oral Investig 2011; 15: 609-615.

117. Pirie M, Linden G J, Irwin C R. Intra-pregnancy non-surgical periodontal treatment and pregnancy outcome-a randomized controlled trial.

J Periodontol 2013: 84: 1391-1400.

118. Rosa M I, Pires P D, Medeiros L R, Edelweiss M I, Martinez-Mesa J. Periodontal disease treatment and risk of preterm birth: a systematic review and metaanalysis. Cad Saude Publica 2012; 28: 1823-1833.

119. Michalowicz B S, Gustafsson A, Thumbigere-Math $V$, Buhlin $K$. The effects of periodontal treatment on pregnancy outcomes. J Periodonto/ 2013; 84(4S): S195-S208.

120. Sanz M, Kornmann K. Periodontitis and adverse pregnancy outcomes: consensus report of the Joint EFP/AAP Workshop on Periodontitis and Systemic Diseases. J Clin Periodonto/ 2013; 40: S164-S169.

121. Quirynen M, Bollen C M, Vandekerckhove B N Dekeyser C, Papaioannou W, Eyssen H. Fullvs. partialmouth disinfection in the treatment of periodontal infections: short-term clinical and microbiological observations. J Dent Res 1995; 74: 1459-1467.

122. Turner Y, Ashley F P, Wilson R F. Effectiveness of oral hygiene with and without root planing in treating subjects with chronic periodontitis. Br Dent J 1994; 177: 367-371. 